Keywords: Methadone Maintenance Program, QEEG, Slow activity, Opiate dependence.

\title{
QEEG mapping and methadone
}

M. Domingo Gorricho* J.R. Valdizán Usón ${ }^{\star \star}$

* Unidad de Asistencia y Seguimiento de Adicciones. Zaragoza

** Servicio de Neurofisiología Clínica. Hospital Universitario Miguel Servet, Zaragoza

SPAIN

\begin{abstract}
Background and Objectives: The aim of the study was to characterise methadone effects on human brain activity in opiate dependence subjects enrolled in a methadone maintenance program (MMP) for at least six months and steady in their diary oral dose for at least one month.

Methods: Resting QEEG activity was evaluated in fifteen MMP subjects for the delta, theta, alpha and beta frequency band. Each subject participated in two similar sessions of QEEG recording. The interval between sessions were three hours.

Results: Changes in brain activity were shown by QEEG-mapping. MMP subjects showed a decrease in alpha activity and an increase in slow activity. The first QEEG recording showed theta activity and the second displayed delta and theta activity.

Conclusions: Results suggest cognitive dysfunction in MMP subjects.
\end{abstract}

\section{Introduction}

The methadone maintenance programs (MMPs) are developed on the basis of being a pharmacological treatment that replaces a short-life opiate agonist (heroin) by another half-life agonist (methadone).

A number of studies have reported worse execution in MMP subjects when compared with controls or abstinence subjects (Table I). Overall, these studies suggest that methadone treatment produces cognitive dysfunction.

Specka et al. ${ }^{7}$, reviewed eight studies and concluded by reporting worse execution by MMP subjects in terms of attention, visual orientation and eye-hand coordination. Nevertheless, the moderate effect can also be explained by socio-demographic variables. These authors concluded that belonging to 
Table I

Effects of methadone on cognitive and psychomotor functions

\begin{tabular}{|c|c|c|c|}
\hline study & subjects & mean dose & results \\
\hline \multirow[t]{2}{*}{ Darke et al., 2000 (1) } & 30 MMP & $78.6 \mathrm{mg}$ & \\
\hline & $30 \mathrm{C}$ & & $\begin{array}{l}\text { MMP significantly worse than } \mathrm{C} \text { in terms } \\
\text { of information processing speed, verbal } \\
\text { and nonverbal learning, problem solving }\end{array}$ \\
\hline Mintzer \& Stitzer, 2002 (2) & $\begin{array}{l}18 \mathrm{MMP} \\
21 \mathrm{C}\end{array}$ & $67.2 \mathrm{mg}$ & $\begin{array}{l}\text { MMP significantly worse than } \mathrm{C} \text { in terms of } \\
\text { psychomotor speed, working memory, } \\
\text { decision making }\end{array}$ \\
\hline Verdejo et al., 2005 (3) & $\begin{array}{l}18 \mathrm{MMP} \\
23 \mathrm{~A}\end{array}$ & $83.82 \mathrm{mg}$ & $\begin{array}{l}\text { MMP significantly worse than A in terms } \\
\text { of processing speed, visuo-espatial attention, } \\
\text { cognitive flexibility }\end{array}$ \\
\hline $\begin{array}{l}\text { Davis \& Liddiard \& McMillan, } \\
2002 \text { (4) }\end{array}$ & $\begin{array}{l}15 \mathrm{MMP} \\
16 \mathrm{~A} \\
14 \mathrm{C}\end{array}$ & $32.5 \mathrm{mg}$ & $\begin{array}{l}\text { MMP worse than A and C but with } \\
\text { significance in word fluency }\end{array}$ \\
\hline Mintzer \& Copersino \& Stitzer, & $\begin{array}{l}18 \mathrm{MMP} \\
20 \mathrm{~A} \\
21 \mathrm{C}\end{array}$ & $67.2 \mathrm{mg}$ & $\mathrm{A}$ in the middle of MMP and $\mathrm{C}$ in many tests \\
\hline Prosser et al., 2006 (6) & $\begin{array}{l}29 \mathrm{MMP} \\
27 \mathrm{D} \\
29 \mathrm{C}\end{array}$ & $73.79 \mathrm{mg}$ & $\begin{array}{l}\text { PMM and D worse than } \mathrm{C} \text { in terms of } \\
\text { function verbal, visual-spatial analysis and } \\
\text { memory, and resistance to distractibility }\end{array}$ \\
\hline
\end{tabular}

MMP: methadone maintenance program subjects; $\mathrm{C}$ : control subjects with no history of substance abuse; A: subjects with history of heroin abuse in abstinence; D: subjects with history of MMP in abstinence

the group of methadone alone was insufficient for predicting impairment in cognitive-psychomotor skills.

Quantitative EEG (QEEG) analysis techniques can provide measurements about information processing because they have a high temporal resolution and employ a standard recording technique ${ }^{8}$. As regards nondependent subjects, morphine and heroin produced changes in EEG recording: slowed alpha frequency, appearance of delta activity and an increase in theta activity ${ }^{9}$.

Alterations in the oscillatory patterns of electrical activity have also been described in heroin-dependence subjects, after withdrawal or after a period of abstinence.

Fingelkurts et al. ${ }^{10}$ reported increases in the beta band (main peak at 19, 20.5, 22 and $23.5 \mathrm{~Hz}$ ) and mostly in the alpha band (main peak at $13.5 \mathrm{~Hz}$ ) with comparing with con- trols. Time without opiate abuse was twelve hours before EEG recording.

Likewise, a significant improvement was observed for alpha (8-13 Hz) and beta (15-21 $\mathrm{Hz}$ ) in subjects in abstinent for 12-15 days ${ }^{11}$.

Polunina and Davydov ${ }^{12}$ described frequency shifts in the alpha 2 range (9.5-12 $\mathrm{Hz}$ ), most prominent in frontal and central derivations, in subjects abstinent between 6 and 60 days who used heroin for at last 18 months, compared with a control group, as well as slowing of alpha 1 range (8.0-9.5 $\mathrm{Hz}$ ) most prominent in central, temporal and occipital derivations in subjects using high dose. The beta range maintained an inverse relationship with abstinence increasing during the two first weeks. If abstinence time was extended, the beta range diminishes.

The above mentioned authors later performed a retrospective study and reported 
greater difficulty in solving the Tower of London neuropsychological test and greater displacement in the alpha 2 range $^{13}$.

Franken et al. ${ }^{14}$ reported increases in the beta 2 band (20-35 Hz) in abstinent subjects for at least two weeks when compared with controls. However, according to these authors none of the frequency bands was significantly related to any of the drug history or craving variables. Left intra-hemispheric gamma frequency $(35-45 \mathrm{~Hz})$ also increased.

Bauer ${ }^{15}$ observed that relapse was most likely when beta activity (19.5-39.8 Hz) was enhanced three months after the beginning of abstinence in subjects with histories of either alcohol, cocaine, cocaine and alcohol, or opiate dependence.

Others patterns of oscillation of electrical activity have been described in research with methadone.

When the subjects start under the acute influence of methadone, they show a reduction in alpha activity and the predominant frequency shifts to $11-12 \mathrm{~Hz}^{9,16}$.

Six subjects (dose between 95-150 mg/day and on the MMP for at least six months) showed a lower percentage of alpha and beta and a larger percentage of delta and theta when compared with control group (frequency band between $0.5-30 \mathrm{~Hz}$ ). These differences were distributed across the whole cortex ${ }^{17}$.

Likewise, the effect of methadone on sleep architecture showed that with dose ranging between 50 and $120 \mathrm{mg} /$ day (and on the MMP for two months or more) ten subjects had less sleep efficiency, more total wake time, less slow waves sleep, less rapid eye movement sleep and more stage 2 sleep than controls ${ }^{18}$.
The use of QEEG to quantify the effects of methadone on dependent subjects has been relatively limited and the studies only employed a limited number of subjects. Given the possibility of alterations on brain electric activity (and given the possibility of cognitive dysfunction), our objective was to determine the extent of such alterations through QEEG parameters. Specifically, we aimed: a) to examine the QEEG parameters for a sample of fifteen MMP subjects; b) to examine the range of QEEG parameters before methadone oral administration and three hours after; c) to produce a spatial representation of QEEG parameters (QEEGmapping).

\section{Materials and methods}

\section{Subjects}

Fifteen methadone maintenance patients with criteria of the Diagnostic and Statistical Manual of Mental Disorders (DSM-IVTR) for opiate dependence ${ }^{19}$, recruited from the outpatient program at the Unidad de Asistencia y Seguimiento de Adicciones (Addiction Treatment and Monitoring Unit) of Nuestra Señora de Gracia Hospital in Zaragoza, Spain.

Thirteen men and two women aged between 29-46 years (mean 38.87 \pm 5.15 ) and with daily oral methadone dose between $50-100 \mathrm{mg} / \mathrm{d}$ (mean $69.33 \pm 16.99$ ). The subjects had been in the MMP for at least six months (mean 59 \pm 33 ) and had maintained steady daily dose for at least one month.

Mean age was $22.73 \pm 5.32$ years when they started using heroin and main routes of administration were intravenous (two subjects), smoking heroin by chasing the drag- 
on (eight subjects), intravenous and smoking heroin by chasing the dragon (five subjects).

Several subjects use psychoactive substances. Some subjects reported regular (between one day and one week) use of cannabis (two subject), alcohol (two subjects) or benzodiacepines (one subject). Other subjects reported episodic (between one week and one month) use of cannabis (two subjects), cocaine (four subjects) or benzodiazepines (one subject).

Educational level was between primary school education and secondary school education.

Subjects who had been previously diagnosed from Axis 1 or 2 of DSM-IV-TR, with neurological pathologies or HIV infection, were excluded.

All subjects were asked to participate in a study concerning the measurement of brain function. They were indicated that the tests to be performed a) were innocuous and did not entail any risk, and b) required their collaboration. Participants collaborated voluntarily, signing the corresponding informed consent.

\section{Procedure}

QEEG recording was performed at the Servicio de Neurofisiología Clínica (Clinical Neurophysiology Unit) of the Miguel Servet Hospital in Zaragoza, Spain.

Each subject participated in two similar EEG recording sessions. The duration of each was twenty minutes. The interval between sessions were three hours ( 9 am and $12 \mathrm{am})$. The duration of each EEG recording was five minutes.
During the sessions the participants remained seated, resting with their eyes closed, and in a comfortable atmosphere.

The daily oral dose of methadone was administered after the first EEG recording and after the first session an urine screening was performed to detect the presence of other type to methadone (opiates, cocaine, benzodiazepines, amphetamines).

\section{Instrument of recording}

Electrodes were fixed with conductive paste at twenty sites of an electrode cap according to the International 10/20 system and using the earlobe as a reference (Fp1, Fz, Fp2, F7, F3, F4, F8, T3, C3, Cz, C4, T4, T5, P3, Pz, P4, T6, O1, Oz, O2).

Electro-ocular activity was recorded with two electrodes (one for every eye). Ocular movements over the interval between 50 and $-50 \mu \mathrm{V}$ were rejected.

Electrode impedance was kept below 5 $\mathrm{K} \Omega$. Activity was recorded using a Track Walker digital system (version 2.0) and sampled at $128 \mathrm{~Hz}$ and then filtered with band pass between 0.18 and $35 \mathrm{~Hz}$. The epochs of at least four artifact-free seconds were selected.

The relative power (RP) measurements for the four main bands - delta $(0.5-3.5 \mathrm{~Hz})$, theta $(4-7.5 \mathrm{~Hz})$, alpha $(8-12.5 \mathrm{~Hz})$ and beta (13-30 Hz) - were calculated.

QEEG recording was performed by a expert from the Servicio de Neurofisiología Clínica and the data were reviewed on the computer screen in order to avoid epochs with ocular movements, drowsiness or any other visually identifiable artifact. If the QEEG expert noted drowsiness during recording, the subject was aroused with noise. 


\section{Statistical analyses}

The T-test was used for comparison paired data for each frequency band (delta, theta, alpha and beta) and for each recording to $\mathrm{P}<0.05$. Normative values were used to determine whether a parameter measured on a subject lies inside or outside the range of normal values.

\section{Results}

\section{Results of first EEG recording}

Of the fifteen subjects, only one displayed normal activity with a significant alpha background rhythm. Nine subjects showed slower activity (theta activity). The rest had unstable background rhythm with no predominance but smaller oscillations than in the previous cases (Figure 1).

\section{Results of second EEG recording}

Subjects displayed no side effects three hours after daily oral methadone intake. No significant differences were observed in background rhythm in almost all cases, with continued predominance of theta activity, albeit with a greater increase in its power and extension to larger number of regions. Slower activity was observed and three subjects showed a significant increase for delta activity (Figure 1).

\section{Urine screening}

The following substances were detected in urinalysis: benzodiazepines (three subjects), cocaine (one subject), opiates and cocaine (three subjects).

\section{Discussion}

The present study showed a decrease in alpha activity and an increase in slow activity in MMP subjects. MMP subjects also exhibited a persistent and characteristic pattern of slow activity with predominance of theta and delta rhythms. These changes reflect less activation of the central nervous system and coincide with results published previously $9,16,17$.

Slow background rhythm: the activity in QEEG recording can be considered to reflect the responsiveness of the neurones and the alpha rhythm can be considered as representing the general level of excitability within the central nervous system. When a certain condition slows down this level, the frequency of the background rhythm diminishes and the QEEG recording could then be described as abnormal. In this line, it has been reported that slow rhythm correlates with cerebral dysfunction and different types of clinical diseases ${ }^{20,21}$.

Other conditions associated with slow background rhythm are the development of the life cycle and the transition from wakefulness to sleep ${ }^{22,23}$. During the development of the life cycle, alpha increases from childhood to adulthood and later decreases. In contrast, theta diminishes, increasing during the final part of the life cycle. During the transition from wakefulness to sleep, alpha diminishes while slow rhythm increases.

Methadone and electrical activity of brain: with the exception of one subject with alpha rhythm, the others presented slow (theta) or unstable background rhythms on the first QEEG-mapping. The second QEEG-mapping presented a persistent (theta) and extensive (delta) slow background rhythm. Although a specific functional role cannot be assigned to each fre- 


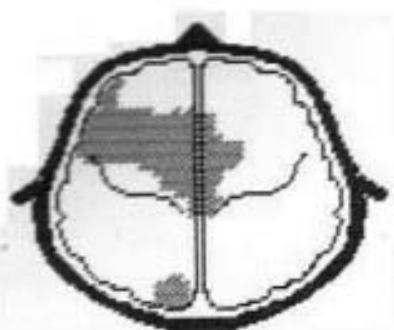

Z RP Delta BB
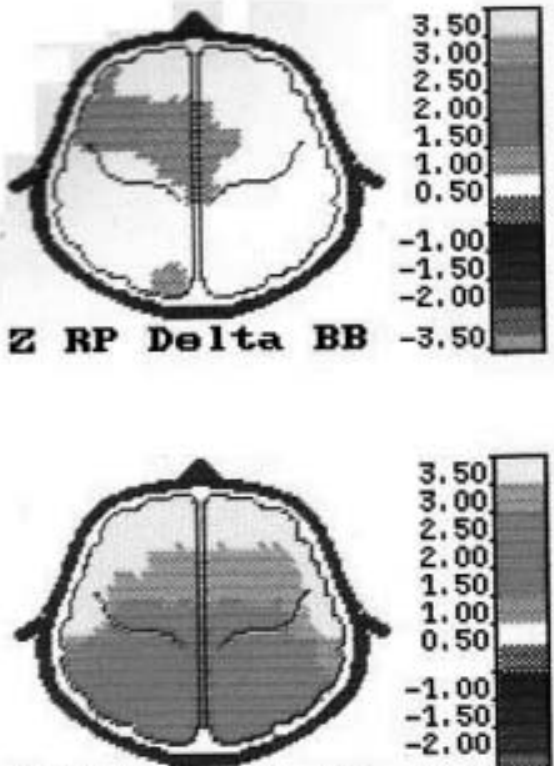

Z RP Theta BB $-3.50 \square$

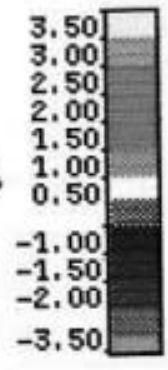

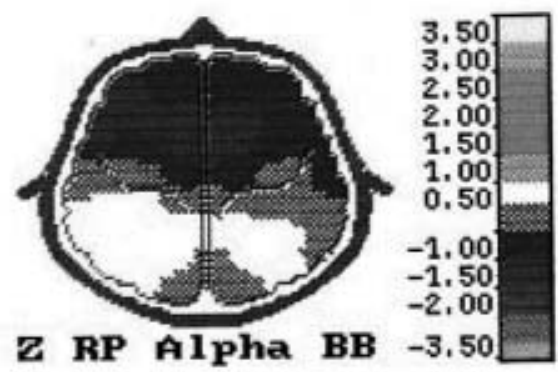
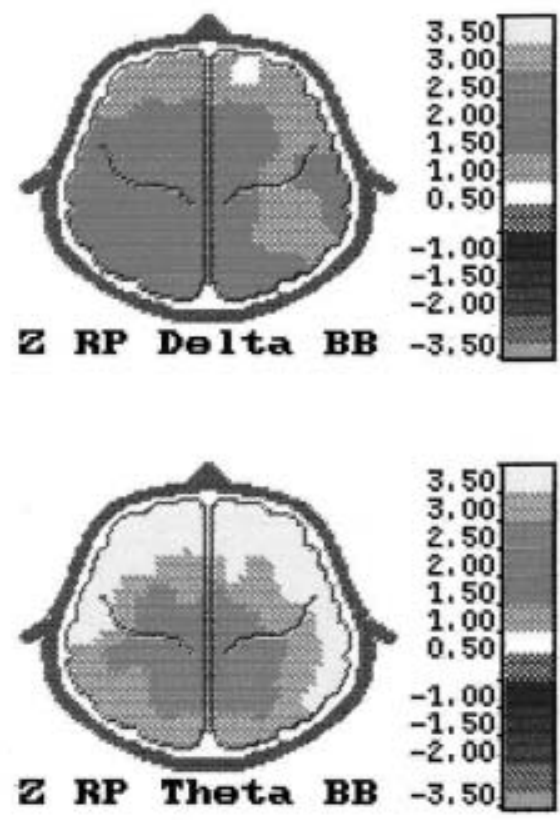

Z RP Theta BB
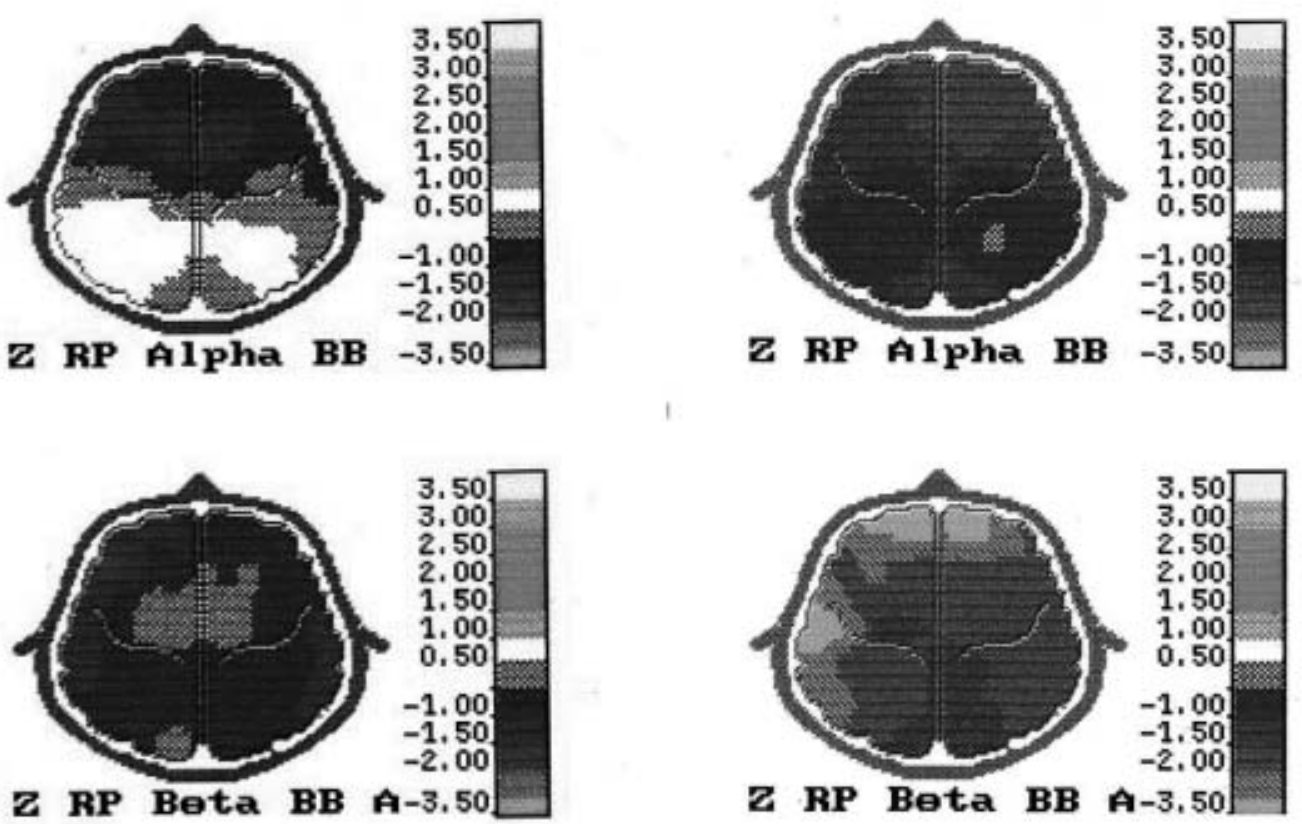

Figure 1. Maps of differences (RP) between first QEEG recording (left) and second QEEG recording (right) for delta, theta, alpha and beta frequency bands (data averaged across all subjects). Yellow and orange represent increases; blue, decreases as compared with normative values $(\mathrm{P}<0.05)$. 
quency band, the presence of slow background rhythm is thought to represent the accumulation and progressive release of methadone. Once in the blood stream, methadone is slowly passed to the brain when it is needed to fill $\mu$ opioid receptors and slow activity can reflect this accumulation and progressive release.

The cause of unstable activity it is not clear. It can reflect the influence of personal variables from an opiate-dependence population, such as different patterns of consumption, polyconsumption, overdose, infections, accidents, or the beginning of methadone withdrawal syndrome or any other substances detected in urinalysis.

Heroin $^{10-12,13}$, cocaine ${ }^{24-26}$ and benzodiacepines $^{27,28}$ increase beta activity. This could be a alternative hypothesis for the first QEEG recording but not for the second. The second QEEG recording did not show unstable activity.

Our approach for studying the acute effect of methadone comprised two similar sessions. This procedure is suitable for determining whether oscillatory activity is persistent or responds selectively to time. In summary, theta activity is a status persistent in MMP subjects between one dose of oral methadone and the next, whereas delta activity maintains an inverse relationship and may increase during the firsts few hours. If time is extended, delta activity diminishes.

Fingelkuts et al. suggest that subjects with opiate dependence have a state of chronic deviation of brain oscillatory systems (beta activity) and methadone can restore the normal temporal structure of brain activity ${ }^{10,17}$. However, like these values (slow activity) still differed from the values for the control subjects (alpha activity) the above mentioned authors reported that the reason may have been the long period of methadone treatment (at least six months) and/or dosage.

Slow background rhythm may coincide with deficits reported in some studies using psychomotor or neuropsichological batteries $^{1-6}$. Nevertheless, while the tasks in these studies demanded a certain degree of execution on the part of the subject, in the present study the proposed task consisted of remaining seated and resting with eyes closed.

In any case, additional research must be performed to differentiate oscillatory patterns due to acute methadone action, as well as to determine the clinical implications for the MMP subjects.

Limitations of the study: the greater number of HIV subjects in the MMP population limited the formation of a sample with no HIV subjects. Although the number of subjects in the sample was a problem, the procedure used in this study still enabled a greater degree of interpretation of data.

Conclusion: the predominance of persistent theta slow activity in MMP subjects was observed. QEEG-mapping allows us to propose methadone as an indicator of bioelectric changes in the oscillation pattern of neuronal populations.

\section{Acknoweledgments}

The authors want to thank Carmen Baranguan, Dr Nieves Domeque, Dr Jesús Ayala from the Unidad de Asistencia $y$ Seguimiento de Adicciones (Nuestra Señora de Gracia Hospital) and to Martina Gracia and Rosa Carpi from the Servicio de Neurofisiología Clínica (Miguel Servet Hospital). 


\section{References}

1. Darke S, Sims J, McDonald S, Wickes W. Cognitive impairment among methadone maintenace patiens. Addiction 2000; 95 (5): 687-695.

2. Mintzer MZ, Stitzer ML. Cognitive impairment in methadone maintenance patients. Drug Alcohol Depend 2002; 67: 41-51.

3. Verdejo A, Toribio I, Orozco C, Puente KL, PérezGarcía M. Neuropsychological functioning in methadone maintenance patients versus abstinent heroin abusers. Drug Alcohol Depend 2005; 78: 283-288.

4. Davis PE, Liddiard H, McMillan TM. Neuropsychological deficits and opiate abuse. Drug Alcohol Depend 2002; 67: 105-108.

5. Mintzer MZ, Copersino ML, Stitzer ML. Opioid abuse and cognitive performance. Drug Alcohol Depend 2005; 78: 225-230.

6. Prosser J, Cohen L, Steinfeld M, Eisenberg D, London E, Galynker I. Neuropsychological functioning in opiate-dependent subjects receiving all following methadone maintenance treatment. Drug Alcohol Depend 2006; 84: 240-247.

7. Specka M, Finkbeiner T, Lodemann E, Leifert K, Kluwig J, Gastpar M. Cognitive-motor performance of methadone maintained patients. Eur Addict Res 2000; 6: 8-19.

8. Knott VJ. Quantitaive EEG methods and measure in human psychopharmacological research. Hum Psychopharmacol Clin Exp 2000; 15: 479-498.

9. Brady JV, Lukas SE. Testing drugs for physical dependence potential and abuse liability. National Institute on Drug Abuse Research Monograph 52. Rockville: Maryland; 1984. (retrieved on May 29, 2007. http://www.nida. nih.gov/pdf/monographs/download52.html)

10. Fingelkurts AlA, Kähkönen S, Fingelkurts A A, Kivisaari R, Borisov S, Puuskari V, Jokela O, Autti T. Reorganization of composition of brain oscillations and their temporal characteristics in opioid dependent patients. Progr Neuropsychopharmacol Biol Psychiat 2006; 30: 1453-1465.

11. Fingelkurts A A, Fingelkurts A A, Kivisaari R, Autti T, Borisov S, Puuskari V, Jokela O, Kähkönen S. Opioid withdrawal results in an increased local and remote functional connectivity at EEG alpha and beta frequency bands. Neuroscience Research 2007; 58: 40-49.

12. Polunina AG, Davydov DM. EEG spectral power and mean frequencies in early heroin abstinence. Progr Neuropsychopharmacol Biol Psychiatry. 2004; 28: 73-82.
13. Davydov DM, Polunina AG. Heroin abusers performance on the Tower of London Test relates to the baseline EEG alpha 2 mean frequency shifts. Progr Neuropsychopharmacol Biol Psychiat 2004; 28: 1143-1152.

14. Franken I, Stam C, Hendriks V, Brink W. Electroencephalographic power and coherence analyses suggest altered brain function in abstinent male heroin dependent patients. Neuropsychobiology 2004; 49: 105-110.

15. Bauer LO. Predicting relapse to alcohol and drug abuse via quantitative electroencephalography. Neuropsychopharmacology 2001; 25: 332-340.

16. Feinstein B. EEG findings in heroin addicts during induction and maintenance on methadone. Electroencephalogr Clin Neurophysiol 1975; 39: 96-99 (abstract).

17. Fingelkurts A A, Fingelkurts A A, Kivisaari R, Autti T, Borisov S, Puuskari V, Jokela O, Kähkönen S. Composition of EEG oscillations and their temporal characteristics: Methadone treatment. Int J Psychophysiol 2007; 64: 130140 .

18. Teichtahl H, Prodromidis A, Miller B, Cherry G, Kronborg I. Sleep disordered breathing in stable methadone programme patients: a pilot study. Addiction 2001; 96 (3): 395-403.

19. American Psychiatric Association. DSM - IV-TR. Manual diagnóstico y estadístico de los trastornos mentales. Barcelona: Masson; 2002.

20. Hughes JR, John ER. Conventional and Quantitative Electroencephalography in Psychiatry. J Neuropsychiatry Clin Neurosci 1999; 11: 190-208.

21. Coutin-Churchman P, Añez Y, Uzcátegui M, Alvarez L, Vergara F, Mendez L, Fleitas R. Quantitative spectral analysis of EEG in psychiatry revisited: drawing signs out of numbers in a clinical setting. Clin Neurophysiol 2003; 114: 2294-2306.

22. Klimesch W. EEG alpha and theta oscillations reflect cognitive and memory performance: a review and analysis. Brain Res Rev 1999; 29: 169-195.

23. Tanaka H, Hayashi M, Hori T. Topographical characteristics of slow wave activities during the transition from wakefulness to sleep. Clin Neurophysiol 2000; 111: 417-427.

24. Costa L, Bauer L. Quantitative electroencephalographic differences associated with alcohol, cocaine, heroin and dual substance dependence. Drug Alcohol Depend 1997; 46: 87-93.

25. Herning R, Guo X, Better W, Weinhold L, Lange W, Cadet J, Gorelick D. Neurophysiological signs of cocaine dependence: increased electroencephalogram beta during withdrawal. Biol Psychiatry 1997; 41: 1087-1094. 
26. Alper K. The EEG and cocaine sensitization: a hypothesis. J Neuropsychiatry Clin Neurosci 1999; 11: 209-221.

27. Patat A. Clinical Pharmacology of Psychotropic Drugs. Hum Psychopharmacol Clin Exp 2000; 15: 361-387.

28. Porjesz B, Almasy L, Edenberg H, Wang K, Chorlian D, Foroud T, et al. Linkage disequilibrium between the beta frequency of the human EEG and a GABAA receptor gene locus. Proc Natl Acad Sci USA 2002; 99 (6): 3729 3733 .

Address for correspondence:

Domingo Gorricho Miguel

E-mail address: domingogorricho@hotmail.com 